\title{
The prediction of different experiences of longterm illness: a longitudinal approach in Sweden
}

\author{
Nelson Blank, Finn Diderichsen
}

\begin{abstract}
Study objective - To analyse the role played by socioeconomic factors and self rated general health in the prediction of the reporting of severe longterm illness, and the extent to which these factors explain social class differences in the reporting of such illness.
\end{abstract}

Design - Analysis of panel data from the survey of living conditions, conducted by Statistics Sweden over the years 1979-81 and 1986-89.

Setting - A random sample of the Swedish population, interviewed in 1979-81 and then re-interviewed in 1986-89.

Participants - A representative sample of 3889 employed Swedish people, aged 16-65 years.

Main results - Socioeconomic and individual factors predict severe longterm illness regardless of the kind of reported disorder from which the subject suffers. The main predictive factor involved is health self rated as fair/poor, but exposure to high physical job demands proved to be the main explanation of the role played by socioeconomic class. There was a significant interaction effect between self rated general health and physical job demands with regard to the experience of severe illness.

Conclusions - The results of the study strengthen the hypothesis that manual workers are not only more exposed to causes of illness that have important individual and social consequences, but also to the personal factors that determine different experiences of illness. Interaction between these two kinds of factors (job demands and self rated health) suggests that socioeconomic and individual factors play different but complementary roles in the causal process leading to the experience of severe longterm illness.

\section{( $(\mathcal{E}$ Epidemiol Community Health 1996;50:156-161)}

While disease refers to a medical view of pathological abnormality indicated by a set of signs and symptoms, illness refers both to a person's feelings of pain and discomfort ${ }^{1}$ and to the psychological and social consequences of having to bear such pain and discomfort. In the view of some medical anthropologists, illness is shaped by cultural and social characteristics, including the experience of sickness. ${ }^{34}$ Young, ${ }^{3}$ for instance, treats sickness as "the process through which worrisome behavioural and biological signs, particularly ones originating in disease, are given socially recognisable meanings, ie, they are made into symptoms and socially significant outcomes". This can be interpreted to mean that the actual degree of suffering experienced by an ill person is influenced by social context and the kind of life disturbance caused by the illness. On these lines, a chronic illness may be conceptualised as an event through which the structures of everyday life are disrupted, ${ }^{5}$ which may have quite specific social and individual consequences. For example, a back pain may be experienced with much greater intensity by a manual worker than a non-manual worker because the former is more likely to experience some restriction in his or her working capacity as a result of that illness; in turn, this may result in a more severe rating of the condition. Thus, self reported morbidity seems to be related to the salience of illness, ${ }^{6}$ not only in terms of actual feelings of distress, but also as a result of interactions between social, psychological, and environmental factors. Few studies, however, have treated severity of illness as an outcome variable, despite the fact that attention has been drawn to its importance. ${ }^{7-10}$

In an earlier study conducted by the current authors (unpublished), a cross sectional design was employed to compare two different experiences of longterm illness (severe and nonsevere) on the basis of the intensity of frequency of symptoms reported. We found that lower socioeconomic classes not only reported a higher prevalence of longterm illness, but also reported their illnesses as being more severe in terms of frequency of symptoms and the discomforts to which they gave rise. Despite this, observed differences between severe and non-severe illnesses in relation to the factors covered by the earlier study (social class, job demands, economic difficulties, social network, and smoking daily) proved to be due to interactions between these factors and other health dimensions, such as subjective health and perceived impairment of personal working capacity. Most of the studied variables could, however, be interpreted as either causes or consequences of illness, and the cross sectional design of the study did not permit us to draw conclusions on causality. The confounding effects of different diagnostic groups (of persons with different diagnosed diseases) were not examined. Nevertheless, the fact that perceived state of health emerged as an interacting variable of fundamental importance in the relationship between perception of severe illness and the studied factors makes it interesting to examine the role of this factor more closely. 


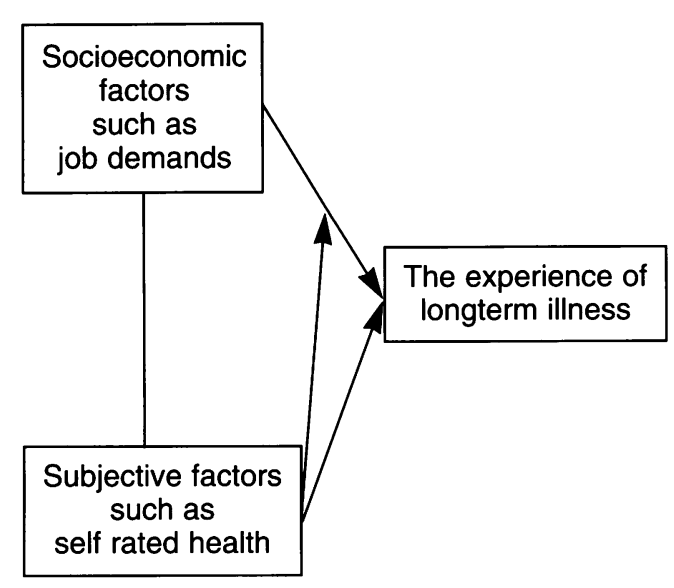

The prediction model for severity of longterm illness.

Earlier studies have shown that health can be self rated as poor even in the absence of any apparent disease, ${ }^{7}$ and also that self rated health is a significant predictor of mortality ${ }^{11-13}$ even in the absence of current disease. ${ }^{14}$ Several authors have pointed out that self rated health combines a variety of physical and emotional components of wellbeing ${ }^{15}$ and life satisfaction. ${ }^{16}$ Thus, it is reasonable to hypothesise that subjective health is an indicator of some of the psychosocial factors involved in the causal process leading to the experience of illness. Naturally, predictors of self reported illness include both specific causes of illness and the stated reasons why people "feel" their illness in different ways. While, in the previous study, we could not distinguish between these "two causes", making the distinction itself raises the question of whether it is possible to improve our knowledge of the relationship between social factors, to be regarded more or less directly as causes of illness (for example, job demands), and the subjective factors (for example, perceived state of health) that have been supposed to have a strong association with the way a specific illness is experienced.

Accordingly, the purposes of the present study are to analyse the role played by a selection of socioeconomic factors and also subjective health (in the absence of chronic illness) in the prediction of different experiences of illness (severe and non-severe), and to analyse the extent to which such factors also explain social class differences in the reporting of severity of illness. The figure illustrates our hypothesis that socioeconomic and subjective factors are inter-correlated and play both an independent and complementary role in determining the way illness is experienced. We address the following specific questions:

- Are experiences of severe and non-severe longterm illness predicted by the factors under study? - Do manual workers show a higher probability than non-manual workers of reporting severe illness? If so, can this be explained by varying prevalences of disorders (different diagnostic groups) between socioeconomic classes? - To what extent is the predictive power of social class with regard to severe illness explained by the factors under study?
- To what extent do these factors explain social class differences in the severity of longterm illness seven or eight years later?

- Is self rated general health in people with no chronic illness a predictor of the reporting of severe illness? If so, does it interact with socioeconomic factors in the determination of the experience of severe illness?

\section{Methods}

This longitudinal study uses a data set from the survey of living conditions (ULF) undertaken by Statistics Sweden. The main purpose of the survey is to collect individual data from a representative sample of the Swedish population, which can then be used for the continuous description and analysis of the distribution of welfare. The proportion of nonrespondents is about $20 \%$, but there are no important differences in response rates between genders or age groups. ${ }^{17}$ No information is available, however, on the socioeconomic classes to which non-respondents belong.

Over the years 1979-81, 24421 people aged 16-74 years were interviewed. A random subsample of 9300 subjects was re-interviewed between 1986 and 1989 - that is seven to eight years later. Those first interviewed in 1979 were re-interviewed in 1986-87, and those interviewed in 1980-81 were re-interviewed in 1988-89. The empirical base for the current study of subjects extracted from this population was defined in accordance with three criteria: subjects had to be $16-65$ years old at the time of the first interview (T1); they had to be employed during the week preceding $\mathrm{T} 1$; and they did not report any longterm illness at T1. Altogether 3889 individuals met the inclusion criteria (2210 men and 1769 women) and comprise the cohort in this study.

A measure of longterm illness was created from responses to a combination of questions: "Do you suffer from any longterm disease/illness, effects of injury, disability, or weakness?" In the case of an affirmative response, the interviewer inquired further: "Could you elaborate on this a little more?", "What did the doctor say it was?", "What part of the body is affected?". Other questions, such as "In addition, do you have any other longterm illness, or suffer from the effects of injury, disability or weakness?" and "Do you take regular medication for anything else?", were included to cover conditions not reported in response to the preceding questions. In total, $24.9 \%$ (967 people) reported at least one illness on the second occasion of interview (T2).

The illnesses reported were later classified and coded by specially trained raters from Statistics Sweden in accordance with the Swedish version of the International Classification of Diseases, ICD8 for $1979-86^{18}$ and ICD9 for 198789. ${ }^{19}$

A measure of the severity of illness constructed using three questions on duration ("When did the illness start?"), on frequency ("How often do you suffer from the effects of the illness?"), and intensity ("How much does your illness bother you?"). We regarded as 
Table 1 Classification of self reported longterm illness according to severity based on the frequency and discomfort of symptoms ( $S=$ severe and $N S=$ non-severe $)$

\begin{tabular}{lllll}
\hline \multirow{2}{*}{ Discomfort } & \multicolumn{2}{l}{ Frequency } & & \\
\cline { 2 - 5 } & Seldom & Now and then & Often & All the time \\
\hline Minor & NS & NS & NS & NS \\
Moderate & NS & NS & S & S \\
Serious & NS & S & S & S \\
Very serious & NS & S & S & S \\
\hline
\end{tabular}

longterm illnesses only complaints of more than three months' duration. As shown in table 1, a composite variable was created, with two values for severity of illness: severe $(n=491)$ and non-severe $(n=476)$. Subjects were regarded as having a severe illness if any one of the illnesses they reported fulfilled the severity criteria. The rationale for constructing the measure in this way lay in our presumption that the intensity and frequency of reported illness reflect the importance such illness has for the individual. Thus, for example, a discomfort that is perceived as only moderate but occurs frequently is regarded as being sufficiently serious to disturb the person's everyday life in some way, and is therefore regarded as severe.

Three variables were analysed as potential background confounders: (1) gender, (2) age (16-39 or 40-65) and (3) immigrant status (born in Sweden or not born in Sweden). A measure of socioeconomic class at $\mathrm{T} 1$ was used - comparing "manual workers" with "nonmanual workers" in line with the socioeconomic classification generally used in Sweden. $^{20}$ At T2, 638 subjects were no longer employed, for they had either retired or become housewives, students or self employed. A new socioeconomic distribution was established: those workers who had retired were classified as non-manual or manual according to their socioeconomic class at time of retirement; others, namely the self employed, housewives, and students, were grouped together as "other classes". All analyses were performed controlling for the variable "employment status" (employed or not employed).

Four variables were treated as representing potential exposure to severe illness.

- The variable physical job demands (high or low) was constructed on the basis of the following five aspects of work: lifts heavy loads on daily basis, monotonous working movements, inappropriate working positions, jolts and vibrations, breaks into sweat on daily basis. A dichotomous category variable (below and above the median) was created, with the value "high" being attributed to physical job demands if two or more of these conditions were met.

- Psychological job demands (high or low) were estimated on the basis of combinations of responses to two questions: "Is your job hectic?" and "Is your job mentally strenuous?" An affirmative response to either question was regarded as sufficient for the subject to qualify as facing high exposure to psychological job demands.

- Economic difficulties (yes or no): the respondent was unable to raise a certain amount of money (10000 Swedish kroner) within a week; and/or the respondent had difficulty managing running expenses over the past year, forcing him or her to borrow from relatives or friends to buy food or pay the rent, to apply for public assistance for food or rent, or to pay the rent after the due date.

- Self rated general health (excellent/good or fair/poor) was based on the question "How do you judge your general state of health?"

The effect measure used in this study was the odds ratio for severe illness; $95 \%$ confidence intervals were calculated by means of multivariate logistic regression. The importance of each factor to the explanation of differences in the reporting of severe illness between individuals was assessed from the proportion of the residual deviance in the full model accounted for by each variable separately. This proportion was obtained by dividing the reduction in deviance generated by the inclusion of a variable in the model containing all variables (except this particular one) by the deviance of the full model (containing all variables). The deviance is used to assess the significance of independent variables when constructing multivariate logistic regression models. ${ }^{21}$

In order to analyse the influence of specific diagnoses on differences in the reporting of severe illness between manual and non-manual workers, we selected two rather prevalent groups: persons suffering from locomotive disorders (ICD/9 710-738) and those with cardiovascular disorders (ICD8: 390-458; ICD9: 390-459).

Interaction effects between variables were evaluated as departures from the additivity of effects (odds ratios). Such a procedure is suitable for testing the hypothesis that different factors have a role to play in the same causal step within the process that leads to the tested outcome. ${ }^{22}$ Odds ratios corresponding to the joint effects were calculated by means of logistic regression, using indicator variables. Two variables representing the presence of each factor in the absence of the other, and a third representing the presence of both factors, were constructed. The reference group consisted of people unexposed to either factor. A synergy index (SI), with $95 \%$ confidence interval, was also calculated. ${ }^{23}$ The index indicates the strength of interaction, and consists in the ratio of observed effect given joint exposure to the effect predicted for joint exposure assuming additivity of effects. No interaction corresponds to $S I=1$, synergism to $S I>1$ and antagonism of effects to $\mathrm{SI}<1 .{ }^{24}$

\section{Results}

Of all reported illnesses at T2, $34 \cdot 2 \%$ were disorders of the locomotive system and $20 \cdot 2 \%$ were cardiovascular disorders. However, $73.0 \%$ of the locomotive disorders, but only $25.6 \%$ of the cardiovascular ones, were reported as severe. This is not a surprising result: musculoskeletal problems are likely to involve painful conditions that limit working capacity; by contrast, cardiovascular disorders include a large number of conditions, such as hypertension $(64 \%$ of all 
Table 2 Odds ratios (95\% CI) for locomotive and cardiovascular disorders classified as severe for the studied variables (models derived by means of multivariate logistic regression with persons not ill or with non-severe locomotive or cardiovascular disorders as the reference group)

\begin{tabular}{lll}
\hline & Locomotive disorders & Cardiovascular disorders \\
\hline 40-65 years & $1 \cdot 72(1 \cdot 29,2 \cdot 28)$ & $6 \cdot 44(3 \cdot 34,12 \cdot 40)$ \\
Women & $1 \cdot 37(1 \cdot 04,1 \cdot 80)$ & - \\
Immigrant & $1 \cdot 71(1 \cdot 14,2 \cdot 51)$ & - \\
Manual workers & $1 \cdot 59(1 \cdot 15,2 \cdot 21)$ & - \\
Physical job demands & $1.55(1 \cdot 14,2 \cdot 11)$ & $1 \cdot 92(1 \cdot 08,3 \cdot 42)$ \\
Psychological job demands & - & - \\
Economic difficulties & $1 \cdot 38(0 \cdot 99,1 \cdot 95)$ & $2 \cdot 07(1 \cdot 02,4 \cdot 23)$ \\
Fair/poor health & $4 \cdot 27(2 \cdot 83,6 \cdot 45)$ & $2 \cdot 74(1 \cdot 12,6 \cdot 71)$ \\
\hline
\end{tabular}

Table 3 Odds ratio (95\% CI) for severe illness, severe illness excluding locomotive disorders and non-severe illnesses for the studied variables (models derived by means of multivariate logistic regression with those not ill as the reference group)

\begin{tabular}{llll}
\hline & Severe illness & $\begin{array}{l}\text { Severe illness excluding } \\
\text { locomotive disorders }\end{array}$ & Non-severe illness \\
\hline 40-65 years & $2.07(1.68,2.55)$ & $2.37(1.81,3.11)$ & $2.80(2.30,3.41)$ \\
Women & $1.33(1.09,1.63)$ & $1.33(1.02,1.73)$ & - \\
Immigrant & $1.33(0.96,1.84)$ & - & - \\
Manual workers & $1.47(1.15,1.87)$ & $1.33(0.97,1.84)$ & $1.23(1.01,1.50)$ \\
Physical job demands & $1.44(1.14,1.81)$ & $1.35(0.99,1.83)$ & - \\
Psychological job demands & $1.30(1.05,1.61)$ & $1.45(1.09,1.92)$ & - \\
Economic difficulties & $1.51(1.17,1.95)$ & $1.59(1.13,2.23)$ & - \\
Fair/poor health & $3.33(2.36,4.70)$ & $2.62(1.65,4.15)$ & $1.53(0.98,2.37)$ \\
\hline
\end{tabular}

cardiovascular disorders) which may not have such an effect.

Table 2 shows that all the studied factors (measured at T1) with the exception of high psychological job demands predict the reporting of locomotive disorders as severe seven/eight years later, with manual workers having a $59 \%$ higher probability than non-manual workers of reporting severe illness even after controlling for other determinants. Economic difficulties, high physical job demands, and fair/poor health also differentiate between severe and non-severe illness.

From table 3 we can observe that even when locomotive disorders $(49 \cdot 1 \%$ of all severe illnesses) are excluded from the analysis, the pattern remains almost the same, with the exception of the influence of the variable "immigrant status". Nevertheless, only age, manual class, and fair/poor health predict nonsevere illness. These results indicate that the higher risk of developing a severe illness to be found among manual workers rather than nonmanual workers may not be explained solely by the fact that the former show a higher incidence of disorders likely to restrict working activities.
In the light of the fact that people reporting non-severe illnesses did not differ importantly from those not reporting any illness in relation to the variables studied, we decided to merge the two categories to form the control group for further analysis. Accordingly, in table 4 we display the odds ratios for severe illness of each factor after controlling for the background variables (models I-VI) and the contribution made by each of them to accounting for deviance in the full model (the model that indicates all the variables under study). The full model demonstrates the major contribution of the variable "self rated general health". Even after controlling for all variables, people who rated their health as fair/poor had a 3.09 higher probability of reporting severe illness seven/ eight years later. Furthermore, subjective health accounted for $1.44 \%$ of the deviance in the model, being even more important than age in explaining variation in the reporting of severe illness between individuals.

However, in explaining class differences relative to severe illness, exposure to high physical job demands proved to be the more important factor. This can be discerned by considering the reduction in the odds ratio for manual workers when each variable is included (see revised models III-VI) compared with model II where only background variables and social class are included. In fact, we note that the odds ratio for manual workers in the full model is exactly the same as in model III. Although including economic difficulties and fair/poor health reduces the effect of social class, the effect of these two variables is in part confounded by the impact of high psychological job demands, which increases the odds ratio for social class. High psychological job demands prove to be a predictor of severe longterm illness, particularly in the case of non-manual workers.

Table 5 shows the same analysis performed as for table 4 , but with social class at $\mathrm{T} 1$ substituted for social class at T2. The results are basically unchanged: high physical job demands remain the main factor explaining differences in the experience of severe illness between manual and non-manual workers. It is interesting to note, moreover, that "other classes" $(60 \cdot 2 \%$ consisting of self employed

Table 4 Odds ratios (95\% CI) for severe illness in relation to persons not ill plus those with non-severe illnesses for the studied variables, and the contribution of each variable to the full model

\begin{tabular}{|c|c|c|c|c|c|c|c|c|}
\hline & \multicolumn{7}{|c|}{ Multivariate logistic models } & \multirow{2}{*}{$\begin{array}{l}\% \text { deviance } \\
\text { accounted for }\end{array}$} \\
\hline & $I$ & II & III & $I V$ & $V$ & $V I$ & Full model & \\
\hline $\begin{array}{l}40-65 \text { years } \\
\text { Women } \\
\text { Immigrant } \\
\text { Manual workers } \\
\text { Physical job demands } \\
\text { Psychological job demands } \\
\text { Economic difficulties } \\
\text { Fair/poor health }\end{array}$ & $\begin{array}{l}1.63 \\
(1.34,1.97) \\
1.26 \\
(1.04,1.53) \\
1.58 \\
(1 \cdot 17,2 \cdot 15)\end{array}$ & $\begin{array}{l}1 \cdot 70 \\
(1 \cdot 40,2 \cdot 06) \\
1 \cdot 30 \\
(1 \cdot 07,1 \cdot 58) \\
1 \cdot 46 \\
(1 \cdot 07,1 \cdot 99) \\
1 \cdot 71 \\
(1 \cdot 40,2 \cdot 08)\end{array}$ & $\begin{array}{l}1 \cdot 74 \\
(1 \cdot 43,2 \cdot 11) \\
1 \cdot 33 \\
(1 \cdot 10,1 \cdot 61) \\
1 \cdot 48 \\
(1 \cdot 09,2 \cdot 02) \\
1 \cdot 41 \\
(1 \cdot 12,1 \cdot 77) \\
1 \cdot 54 \\
(1 \cdot 23,1 \cdot 93)\end{array}$ & $\begin{array}{l}1 \cdot 71 \\
(1 \cdot 41,2 \cdot 08) \\
1 \cdot 31 \\
(1 \cdot 08,1 \cdot 59) \\
1 \cdot 49 \\
(1 \cdot 09,2 \cdot 04) \\
1 \cdot 84 \\
(1 \cdot 50,2 \cdot 26) \\
\\
1 \cdot 44 \\
(1 \cdot 17,1 \cdot 77)\end{array}$ & $\begin{array}{l}1 \cdot 81 \\
(1 \cdot 48,2 \cdot 21) \\
1 \cdot 30 \\
(1 \cdot 07,1 \cdot 58) \\
1 \cdot 41 \\
(1 \cdot 03,1 \cdot 93) \\
1 \cdot 63 \\
(1 \cdot 33,2 \cdot 00)\end{array}$ & $\begin{array}{l}1 \cdot 65 \\
(1 \cdot 36.2 \cdot 00) \\
1.31 \\
(1 \cdot 08,1 \cdot 59) \\
1 \cdot 36 \\
(0.99,1 \cdot 87) \\
1 \cdot 65 \\
(1 \cdot 35,2 \cdot 01)\end{array}$ & $\begin{array}{l}1 \cdot 75 \\
(1.43,2 \cdot 15) \\
1.32 \\
(1.08,1 \cdot 60) \\
1.35 \\
(0.98,1 \cdot 85) \\
1.42 \\
(1 \cdot 12,1.81) \\
1.42 \\
(1 \cdot 13,1 \cdot 79) \\
1.32 \\
(1.07,1.63) \\
1.47 \\
(1.15,1.89) \\
3.09 \\
(2 \cdot 23,4.30)\end{array}$ & $\begin{array}{l}1 \cdot 06 \\
\mathrm{p}<0 \cdot 0001 \\
0 \cdot 27 \\
\mathrm{p}<0 \cdot 01 \\
0 \cdot 40 \\
\mathrm{p}<0 \cdot 001 \\
0 \cdot 31 \\
\mathrm{p}<0 \cdot 005 \\
0 \cdot 88 \\
\mathrm{p}<0 \cdot 0001 \\
0 \cdot 35 \\
\mathrm{p}<0 \cdot 05 \\
0 \cdot 75 \\
\mathrm{p}<0 \cdot 0001 \\
1 \cdot 44 \\
\mathrm{p}<0 \cdot 0001\end{array}$ \\
\hline
\end{tabular}


Table 5 Odds ratios (95\% CI) for severe illness in relation to persons not ill plus those with non-severe illnesses for the studied variables, analysing those that contributed to socioeconomic-class differences in severe illness at the time of the second interview (T2)

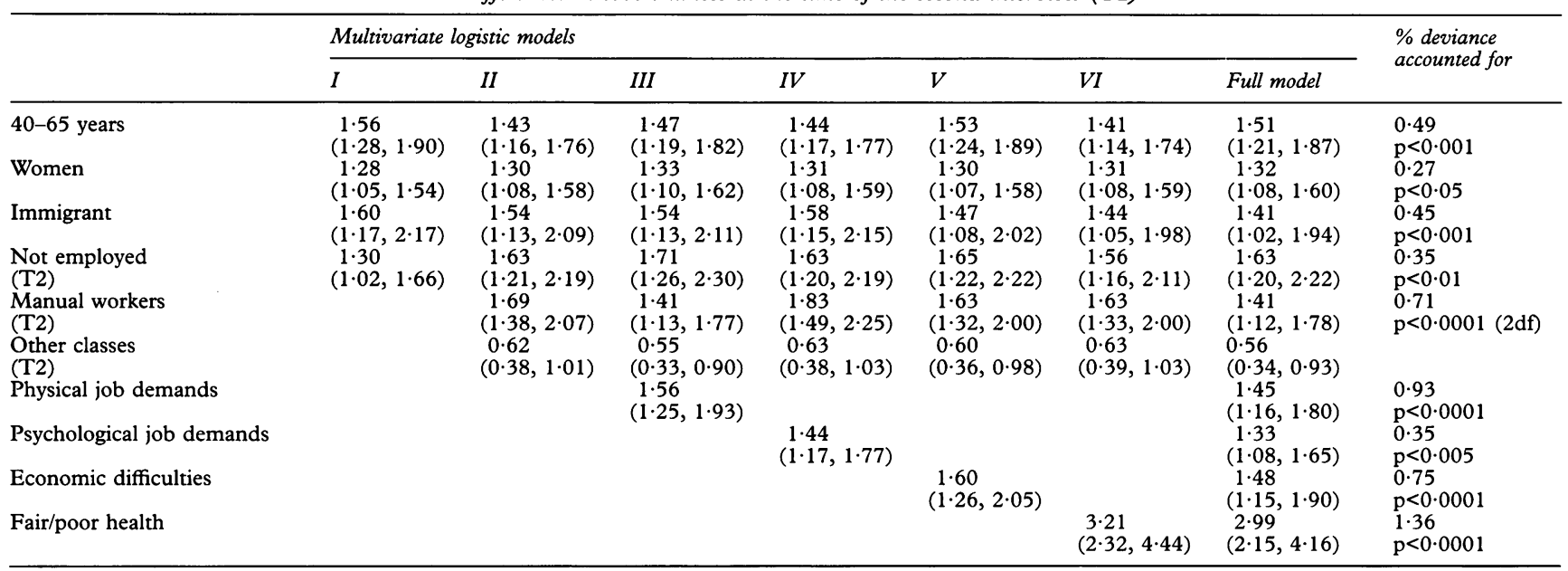

persons) prove to report fewer severe illnesses than non-manual workers. The group of self employed individuals at T2, which stemmed from the group of employed manual and nonmanual workers at $T 1$, seems to be relatively very healthy. After controlling for age, gender, and employment status, all other groups containing individuals who were no longer classified as manual or non-manual workers reported $2 \cdot 24(1 \cdot 25-4 \cdot 02)$ times as many severe illnesses as the self employed group.

Finally, confirming the validity of the predictive model displayed in the figure, exposure to high physical job demands shows a strong association with fair/poor self rated health at T1. Among people in highly physically demanding jobs, $6.7 \%$ rated their health as fair/ poor, in comparison with $3.9 \%$ of those facing low physical job demands $\left(\chi^{2}=15.678\right.$ $\mathrm{p}<0.001)$. In addition, an interaction effect was found between physical job demands and self rated health: the OR $(95 \% \mathrm{CI})$ of being exposed to high physical job demands among those who reported good health was $1.70(1.38,2.09)$; the OR for fair/poor health among those not exposed to high physical job demands was 3.06 $(1 \cdot 84,5 \cdot 09)$; and the combined effect was 6.35 $(4 \cdot 18,9 \cdot 65)$. The synergy index in this case was $1.94(0.94,3.99)$, implying that the effect on severe illness of being exposed to high physical job demands in combination with rating personal health as fair/poor was $94 \%$ greater than would have been expected on the assumption of additivity of effects. No confounding effect was observed when controlling for gender.

\section{Discussion}

The results of the present study clearly show that socioeconomic and individual factors predict the reporting of severe longterm illness regardless of kind of reported disorder. To a lesser extent, self rated health is also a predictor of non-severe illness. The main predictive factor that discriminates between individuals with regard to severity of illness is health self rated as fair/poor. However, exposure to high physical job demands proves to be the main explanatory factor in terms of the role played by socio- economic class in the reporting of severe illness, and also in terms of class differences following the onset of illness.

Our findings concerning class differences are in line with Lundberg's earlier study. ${ }^{25} \mathrm{Al}$ though a quite different outcome measure was employed in that study, the author demonstrated that physical working conditions in conjunction with economic hardship during childhood, and to some extent health related behaviours, were the most important factors in explaining class differences in physical illness in Sweden. Exposures to heavy physical job demands are, undoubtedly, specific causes of physical illnesses such as musculoskeletal disorders; but in our study, the physical-job-demand factor also predicted severe illnesses of the cardiovascular system. This may, however, be due to the confounding effect of physical job demands on other exposures, such as poor decision-latitude at work, ${ }^{26}$ a characteristic that has been associated with cardiovascular disease. ${ }^{27}$ When interpreting socioeconomic variables as "causal factors", however, it should be taken into account that these are often markers for a complex set of social conditions and processes, all of which may be causally involved. ${ }^{28}$

Although not important in explaining class differences, self rated health and economic difficulties were the most important factors in predicting differences in the experiences of severe illness between individuals. In fact, $5 \cdot 0 \%$ of the population not reporting any longterm illness at $\mathrm{T} 1$ rated their health as fair/poor. While it is possible that unreported short term illnesses might explain part of this finding, other studies have shown that self ratings of health and reports of symptoms are not strongly associated. For example, a British study of 2500 subjects revealed that of $95 \%$ of adults who had reported symptoms of illness over the previous 15 days, only $31 \%$ described their health as fair/poor. ${ }^{29}$ Results from another study suggest that reported healthiness is more closely related to people's fears and beliefs concerning disease, and to their tendency to somatize distress, than it is to clinical assessments of medical status. ${ }^{30}$ Further, self rating of health has been 
described as involving relatively stable perceptions over time, ${ }^{13}$ and it is suggested that health is viewed predominantly in psychological terms. ${ }^{3132}$ There is strong evidence in the published reports that subjective health is constituted by psychosocial dimensions such as psychological distress, ${ }^{33}$ life satisfaction and wellbeing, ${ }^{1516}$ or by inadequate coping mechanisms for dealing with life demands. ${ }^{34}$

Although we were not able to test the extent to which subjective health should be regarded as a proxy for certain psychosocial variables, one finding of our study supporting such an interpretation is that health self rated as fair/ poor and economic difficulties are strongly related. At T1 (when unaffected by illness) $8 \cdot 7 \%$ of persons with economic difficulties reported fair/poor health, compared with $4.2 \%$ $(p<0.001)$ of those without economic difficulties. The experience of economic difficulties in our study should be understood as an indicator of relative deprivation (temporary or permanent), involving economic vulnerability and giving rise to psychological strain. ${ }^{35}$

In the light of this, the interaction found between job demands and self rated health strongly suggests that socioeconomic and personal factors may play different but complementary roles in the causal process leading to the experiences of severe longterm illnesses. Mechanic and Angel ${ }^{36}$ for example, in analysing factors associated with self reported back pain, found that physical impairment may contribute to depressed mood at the same time that psychological distress augments the experience of pain. Along the same lines, Turner and $\mathrm{Noh}^{37}$ showed that the physically disabled face a dramatically raised risk of suffering depressive symptoms, and that the severity of their problems is conditioned significantly by degree of function limitation and pain.

One important drawback of the current study is that individuals were observed on only two occasions, before and after the onset of illness. As a result, it was not possible either to follow possible changes over time in relation to the variables or more precisely to differentiate between individuals with regard to the onset of illness. Nevertheless, the longitudinal design of the study enables us to draw certain conclusions concerning causal relations between the studied variables and the severity of longterm illness. The small number of variables analysed within the confines of the study and the relative large residual remaining after data were fitted to the full model suggest that other socio-economic and personal factors must be taken into consideration in further analysis.

Our results strengthen the hypothesis that manual workers are not only more exposed to causes of illness, such as high physical job demands (which also have important social consequences, such as disability or absence from work through sickness), but are also more exposed to psychosocial influences that interact in some manner so as to generate illnesses that are experienced with greater intensity and frequency. How these two aspects interact to produce different experiences of illness is a new and important question that needs to be addressed in research on health inequalities.

The study was supported in the form of grant by CAPES (PostGraduate Education Federal Agency-Brazil) and The Swedish Council of Social Research.

1 Field D. The social definition of illness. In: Tuckett D ed. An introduction to medical sociology. London: Tavistock Publications, 1976;334-66.

2 Radley A. Making sense of illness. London: Sage Publications, 1994.

3 Young A. The anthropologies of illness and sickness. Annals of Revues in Anthropology 1982;11:257-85.

4 Kleinman A, Eisenberg L, Good B. Culture, illness, and care. Ann Intern Med 1978;88:251-8.

5 Bury M. Chronic illness as a biographical disruption. Sociology of Health and Illness 1982;2:167-82.

6 Mechanic D, Newton $M$. Some problems in the analysis of morbidity data. $\mathcal{F}$ Chron Dis 1965;18:269-80

7 Blaxter M. A comparison of inequality in morbidity. In: Fox $\mathrm{J}$ ed. Health inequalities in European countries. Aldershot: Gower, 1989.

8 Statistiska Centralbyrån (SCB). Levnadsförhållanden. Hälsa och sjukvårdskonsumption 1974. Report no 1. Stockholm: Liberförlag, 1976. (In Swedish).

9 Blaxter $M$. Evidence on inequality in health from a national survey. Lancet 1987; ii:30-3.

10 Bucquet D, Curtis S. Sociodemographic variation in perceived illness and the use of primary health care: the value of community survey data for primary case service value of community survey data for prima
planning. Soc Sci Med 1986;23:733-44.

11 Mossey JA, Shapiro E. Self-rated health: a predictor of mortality among the elderly. Am f Public Health 1982;72: 800-8

12 McCallum J, Shadbolt B, Wang D. Self-rated health and survival: a 7-year follow-up study of Australian elderly. Am $\mathcal{f}$ Public Health 1994;84:1110-5.

13 Idler EL, Angel RJ. Self-rated health and mortality in the NHANES-I epidemiologic follow-up study. Am $\mathcal{F}$ Public Health 1990;80:446-52.

14 Prevost AT, Blaxter $M$. Indicators of mortality in health and lifestyle survey in respondents. F Epidemiol Community Health 1993;47:A396.

15 Okun, Stock WA, Haring MJ, Witter RA. Health and subjective well-being: a meta-analysis. International fournal of Aging and Human Development 1984;19:111-32

16 Palmore E, Luikart C. Health and social factors related to life satisfaction. F Health Soc Behav 1972;13:68-80.

17 Statistiska Centralbyrån (SCB). Levnadsförhållanden. Teknisk rapport avseende 1984-85 års, 1986-87 års och 1988-89 års undeersökningar av levnadsförhållanden. Appendix 13 Stockholm: Liber, 1991.

18 Socialstryrelsen. Klassification av sjukdom 1968. 4 uppl. Stockholm, 1981.

19 Socialstryrelsen. Klassification av sjukdom 1987. Stockholm, 1986.

20 Statistiska Centralbyrån (SCB). Socioekonomisk indelningSEI. Stockholm, 1982

21 Hosmer DW, Lemeshow S. Applied logistic regression. New York: Wiley, 1989.

22 Rothman KJ, Greenland S, Walker A. Concepts of interaction. Am f Epidemiol 1980;112:467-70.

23 Thompson WD. Statistical analysis of case-control studies. Epidemiological Reviews 1994;16:33-50.

24 Rothman KJ. Modern epidemiology. Boston: Little, Brown and Co, 1986.

25 Lundberg $O$. Causal explanations for class inequality in health - an empirical analysis. Soc Sci Med 1991;32: 385-93.

26 Karasek R, Theorell T. Healthy work. New York: Basic Books, 1990.

27 Karasek R, Baker D, Marxer F, Ahlbom A, Theorell T. Job decision latitude, job demands and cardiovascular disease: a prospective study of Swedish men. Am $\mathcal{f}$ Public Health 1981;71:694-705.

28 Mcintire S. The patterning of health by social position in contemporary Britain: directions for sociological research. Soc Sci Med 1986;23:393-415.

29 Wadsworth MEJ, Butterfield WJ, Blaney R. Health and sickness: the choice of treatment. London: Tavistock, 1971.

30 Barsky AJ, Clearly PD, Klerman GL. Determinants of perceived health status of medical outpatients. Soc Sci Med 1992;34:1147-54.

31 Blaxter M. Health and lifestyles. Routledge: New York, 1990.

32 van Dalen H, Williams A, Gudex C. Lay people's evaluation of health: are there variations between different subgroups? f Epidemiol and Community Health 1994;48:248-53.

33 Garrity TF, Somes GW, Marx MB. Factors influencing selfassessment of health. Soc Sci Med 1978;12:77-81.

34 Söderqvist S, Bäckman G. Life control and perceived health. Meddelanden fràn Ekonomisk-Statvetenskapliga Fakulteten. Åbo, 1988

35 Towsend P. Deprivation. Fournal of Social Policy 1987;16: 125-46.

36 Mechanic D, Angel RJ. Some factors associated with the Mechanic D, Angel RJ. Some factors associated with the
report and evaluation of back pain. $\mathcal{F}$ Health Soc Behav 1987;28:131-39.

37 Turner RJ, Noh S. Physical disability and depression: longitudinal analysis. $\mathcal{f}$ Health Soc Behav 1988;29:23-37. 